\title{
O CENTRO DA CIDADE E A PRODUÇÃO DOS ESPAÇOS: A APROPRIAÇÃO DAS ÁREAS CENTRAIS POR CAMELÔS NA CIDADE DE VITÓRIA DA CONQUISTA/BA
}

\begin{abstract}
RESUMO
O espaço, ao longo do processo histórico, passou a fazer parte dos circuitos de valorização do capital, de modo que tanto a produção quanto o consumo do espaço, encontram-se inseridos no amplo processo de reprodução das relações de produção capitalistas. A partir dessa percepção, a presente pesquisa apresenta-se como estudo de caso que se propôs a analisar o comércio informal articulado e atrelado às funções do centro como expressão de espaços de consumo, afirmando a centralidade intraurbana. Ademais, procurou-se identificar as áreas de comércio popular, bem como sua estrutura urbana, na busca pelo entendimento da dinâmica do uso do solo e as estratégias locacionais dos camelôs. Foi ainda proposta a análise das formas de regulação do comércio informal, pelo governo municipal, a partir de seus variados instrumentos de controle. Para o desenvolvimento dos objetivos propostos e seguindo a orientação teórica, a pesquisa empírica foi estabelecida com a realização de entrevistas e aplicação de questionários aos comerciantes populares (camelôs) dos dois principais pontos de concentração de comércio informal no centro principal da cidade de Vitória da Conquista/BA, sendo eles a Praça Arlindo Rodrigues e Praça da Bandeira. Fez-se também necessário realizar levantamento documental a partir de pesquisas em órgãos públicos. A pesquisa mostrou por meio da análise das suas formas de organização, disposição espacial, estrutura urbana, e dos aspectos funcional e socioeconômico, a contribuição das atividades comerciais informais para afirmação da centralidade intraurbana, bem como o modo como as mesmas são regularizadas e legitimadas, por meio da atuação do poder público.
\end{abstract}

PALAVRAS-CHAVE: Comércio informal. Centralidade intraurbana. Governo municipal.

\section{CENTER CITY AND THE PRODUCTION OF SPACES: THE OWNERSHIP OF CENTRAL AREAS FOR CAMELS IN VICTORY CITY CONQUEST / BA}

\footnotetext{
${ }^{1}$ Doutoranda em Geografia pela FFC/IGCE da UNESP, campus de Rio Claro.

E-mail: adelu.2010@gmail.com

2 Docente do Curso de Pós-Graduação em Geografia da FCT/UNESP, campus de Presidente Prudente. E-mail: whitacker@uol.com.br
} 
Revista Nacional de

Gerenciamento de Cidades

\section{SUMMARY}

The space along the historical process, became part of the capital appreciation circuits, so that both the production and the consumption of space, are inserted into the broad process of reproduction of capitalist relations of production. From this perception, this research presents a case study that aimed to analyze the articulated informal trade and linked to the center functions as an expression of consumer spaces, affirming the centrality Intraurban. Moreover, it tried to identify the popular shopping areas as well as its urban structure in the search for understanding of the land use dynamics and locational strategies of street vendors. It was further proposed to examine ways of regulating the informal trade, the municipal government, from their various control instruments. For the development of the proposed objectives and following the theoretical orientation, empirical research has been established with interviews and questionnaires to popular traders (hawkers) of the two main points of informal trade concentration in the main center of Vitoria da Conquista / BA, namely Square Arlindo Rodrigues and Flag Square. There was also necessary to carry out documentary survey from research on public agencies. Research has shown through the analysis of their forms of organization, spatial arrangement, urban structure and the functional and socioeconomic aspects, the contribution of informal commercial activities for affirmation of intra-urban centrality, as well as how they are regularized and legitimized, through the government's performance.

KEYWORDS: Informal trade. Centralization Intraurban. Municipal government.

\section{CENTRO DE LA CIUDAD Y LA PRODUCCIÓN DE ESPACIOS: LA PROPIEDAD DE ÁREAS CENTRALES PARA CAMELLOS EN LA VICTORIA DE LA CIUDAD CONQUISTA / BA}

\section{RESUMEN}

El espacio a lo largo del proceso histórico, se convirtió en parte de los circuitos de apreciación de capital, de modo que tanto la producción como el consumo de espacio, se insertan en el amplio proceso de reproducción de las relaciones capitalistas de producción. Desde esta percepción, esta investigación presenta un caso de estudio que tuvo como objetivo analizar el comercio informal articulado y vinculado a las funciones del centro como una expresión de los espacios de consumo, afirmando la centralidad intraurbanos. Por otra parte, hemos tratado de identificar las zonas comerciales, así como su estructura urbana en la búsqueda de la comprensión de la dinámica de uso del suelo y estrategias de ubicación de los vendedores ambulantes. Se propuso además examinar formas de regular el comercio informal, el gobierno municipal, de sus diversos instrumentos de control. Para el desarrollo de los objetivos propuestos y siguiendo la orientación teórica, la investigación empírica se ha establecido con entrevistas y cuestionarios a los comerciantes populares (vendedores ambulantes) de los dos puntos principales de concentración del comercio informal en el principal centro de Vitoria da Conquista / BA, a saber, la Plaza Arlindo Rodrigues y Plaza de la Bandera. También era necesario llevar a cabo la encuesta documental de la investigación sobre las agencias públicas. La investigación ha demostrado mediante el análisis de sus formas de organización, arreglo espacial, la estructura urbana y los aspectos funcionales y socioeconómicos, la contribución de las actividades comerciales informales para la afirmación de la centralidad intraurbana, así como la forma en que estén regularizadas, y legitimadas, a través de la actuación del gobierno. 


\section{Revista Nacional de}

Gerenciamento de Cidades

PALABRAS CLAVE: El comercio informal. Centralización intraurbanos. Gobierno municipal.

\section{Introdução}

Entendido como condição geral de existência e reprodução da sociedade, observa-se que ao longo da história do modo de produção capitalista, o espaço passou a fazer parte dos circuitos de valorização do capital. Para um melhor entendimento dessa questão, é preciso considerar que tanto a produção quanto o consumo do espaço, particularmente do espaço urbano, encontram-se inseridos no amplo processo de reprodução das relações de produção capitalistas, regulando-se pelas necessidades do capital em gerar valor excedente, bem como pelos ditames da propriedade privada, uma vez que o valor de troca se sobrepôs historicamente ao valor de uso (BOTELHO, 2007).

Botelho (2007) ainda considera que a relação entre o espaço e o modo de produção capitalista, deve ser vista como sendo dialética e complexa, uma verdadeira via de mão dupla.

Ao que se refere ao entendimento da produção do espaço urbano como estratégia do capital, na presente pesquisa são destacados principalmente dois apontamentos sobre a cidade: o comércio e o consumo, além dos elementos que compõem a organização e regulação das atividades entendidas aqui como informais, bem como as estratégias de localização das mesmas como parte do processo de afirmação da centralidade intraurbana.

Assim, foi desenvolvida a perspectiva da análise do comércio informal articulado e atrelado às funções do centro como expressão de espaços de consumo, frente à popularização e generalização dos produtos, na especificidade do centro principal da cidade de Vitória da Conquista/BA (Figura 1). Tem-se como fator primordial a convergência das atividades para a respectiva área, expressa pelos fluxos nela estabelecidos, o que acaba por remeter a discussão sobre as estratégias 


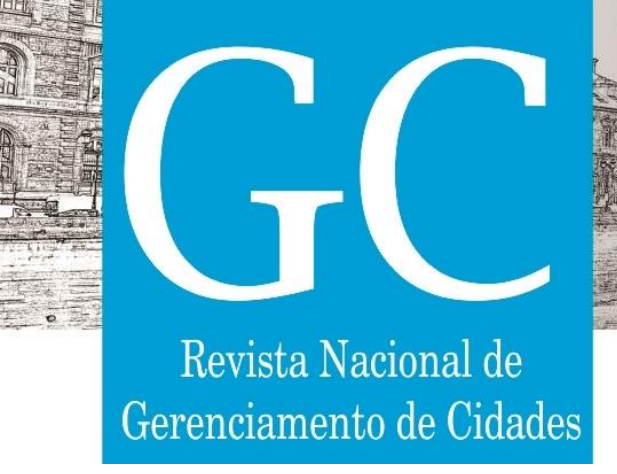

do comércio de rua e a estruturação dos camelódromos, levando-se ainda em consideração as condições de trabalho e o perfil dos trabalhadores na informalidade.

Vitória da Conquista abrange uma área de $3.704,018$ km² com uma população estimada pelo IBGE, em 2014, de 340.199 habitantes, sendo a terceira maior cidade do estado e a quarta do interior do Nordeste. Esta cidade se estabelece ainda como principal centro regional, polarizando mais de 40 municipios na Bahia e no norte do estado de Minas Gerais, estando entre os 100 maiores centros urbanos do país (ABREU, 2011).

Para o desenvolvimento dos objetivos propostos e seguindo a orientação teórica, a pesquisa empírica foi estabelecida com a realização de entrevistas e aplicação de questionários a 146 trabalhadores informais dos dois principais pontos de concentração de camelôs no centro principal de Vitória da Conquista/BA (sendo eles a Praça Arlindo Rodrigues - Feira do Paraguai - e a Praça da Bandeira), correspondendo a uma amostra de $40 \%$ de uma população de 364 trabalhadores informais dessa localidade, representando um conjunto tendencial importante e significativo para a análise. Procurou-se assim buscar compreender as relações socioeconômicas sob as quais essas atividades se realizam, os agentes envolvidos, sua disposição espacial, bem como a articulação com as demais áreas em seu entorno. 


\section{Revista Nacional de}

É importante ainda esclarecer que nessa pesquisa não se teve a intenção de discutir os problemas atrelados à categoria do trabalho informal, ou seja, a ideia está relacionada à presença das bancas dispostas em praças e calçadas, além do camelódromo, associados aos espaços de consumo no centro, expressando e reforçando a centralidade a partir das formas e funções.

\section{Desenvolvimento}

\section{1 discussões acerca dos processos de produção e apropriação do espaço}

De um modo geral, considera-se o espaço geográfico sendo formado por um conjunto solidário, indissociável e também conflitante de sistema de objetos e sistema de ações, não considerados isoladamente. Santos (2004) afirma que as ações humanas dependem do objetivo e da finalidade com a qual é praticada, não se restringindo aos indivíduos, incluindo, também, as empresas e as mais diversas instituições existentes. Já o sistema de objetos, que em conjunto com as ações formam o espaço geográfico, é tudo o que existe na superfície da Terra, toda herança da história natural e todo resultado da ação humana que se objetivou, podendo a cidade ser citada como exemplo.

Especificamente com relação a cidade, Lefebvre (1972) destaca o seu importante papel enquanto lugar onde se produzem e trocam os bens, onde são consumidos, uma vez que a mesma concentra populações, os instrumentos de produção, o capital, as necessidades e as fruições. Assim, além da compreensão do processo de produção do espaço, acredita-se ser igualmente importante a busca pelo entendimento do modo pelo qual se efetiva a sua apropriação, entendendo-se que a produção da sociedade se realiza como apropriação/produção do espaço (CARLOS, 2007).

Visando-se uma melhor compreensão dessa questão, Lencione e Carlos (1982) apontam para a importância de se considerar as condições específicas e históricas de uma dada sociedade, como sendo determinantes nesse processo de 


\section{Revista Nacional de}

efetivação da apropriação do espaço. Desse modo, ambas acreditam que, sob o capitalismo, o processo de produção do espaço condiz também ao processo capitalista de consumo que, por sua vez, se traduz pela propriedade privada do espaço. Assim, o espaço geográfico pode então ser analisado como espaçomercadoria, sendo que, sob a formação econômica social capitalista, o valor do mesmo é dado pela sua posição de ocupação dentro do espaço global (LENCIONI; CARLOS, 1982).

Contudo, é importante frisar que na presente pesquisa as atenções encontramse voltadas de forma específica para a apropriação das áreas centrais por camelôs na cidade de Vitória da Conquista/BA, procurando-se analisar suas estratégias comerciais articuladas e atreladas às funções do centro como expressão de espaços de consumo, afirmando a centralidade intraurbana.

Enfoca-se, assim, o aspecto da produção/reprodução social dos espaços (por meio das estratégias comerciais), pensado no âmbito de determinados sujeitos com a oferta do que é entendido aqui por comércio informal. Para Carlos (2007), essa relação espaço-sociedade, acaba por sinalizar uma compreensão da dialética entre ambos, como um termo que se realiza no outro e através do outro.

Evidencia-se, ainda, a dinâmica do uso do solo urbano na área central da referida cidade, de modo que quem pode pagar o seu preço se beneficia das melhores localizações, sendo que no sistema capitalista de produção, as estratégias comerciais e as novas formas espaciais vislumbram esse processo (SPOSITO, 1991). Tudo isso remete ao entendimento do centro como uma mercadoria e o uso do solo como um mecanismo de mercado, o que nos conduz a compreensão da cidade como sendo "[...] espaços divididos socialmente e economicamente no sentido da própria funcionalidade que assume diante das formas que agrupa." (MONTESSORO, 2006, p. 71).

Assim, na escala do espaço intraurbano em questão, pode-se verificar uma diferenciação socioespacial traduzindo-se na divisão econômica do espaço, que se encontra fortemente articulada e interdependente com a divisão social do espaço 


\section{Revista Nacional de}

Gerenciamento de Cidades

(CORREA, 2007), isso levando em consideração padrões de uso do solo definidores de setores da zona periférica do centro, das áreas comerciais.

Desse modo, para um melhor entendimento da temática, torna-se necessário analisar os espaços de consumo referentes às áreas de comércio popular do centro principal da cidade de Vitória da Conquista, ao que diz respeito a sua organização; disposição espacial; produtos comercializados (aspecto funcional); procedência das mercadorias; mercado de consumo (aspecto socioeconômico); bem como a sua estrutura urbana, de modo a compreender a articulação com as demais áreas em seu entorno.

\subsection{Principais áreas de comércio popular na cidade de Vitória da Conquista/BA: dinâmica do uso do solo urbano e as estratégias locacionais dos camelôs}

No centro comercial de Vitória da Conquista, observa-se um uso comercial e de prestação de serviços muito diversificados e uma organização socioespacial bastante complexa, bem como uma grande circulação e fluxos de pessoas, mercadorias e capitais, que possibilitam o consumo e a dinâmica econômica desse espaço. Desse modo, podese dizer que o centro comercial conquistense ainda mantém-se como espaço de concentração das principais atividades econômicas.

Os espaços de consumo que a presente pesquisa se propõe analisar consistem nos dois principais pontos de concentração de comércio popular no centro principal da referida cidade, sendo eles a Praça Arlindo Rodrigues (Feira do Paraguai) e a Praça da Bandeira, conforme dito anteriormente, visando-se o entendimento dos mesmos no contexto da cidade capitalista, enquanto espaço de produção e riqueza, orientada para o consumo.

Na supracitada 'Feira do Paraguai' (situada na Praça Arlindo Rodrigues), atualmente há a presença de 179 blocos (barraquinhas), em quais são comercializadas uma grande variedade de mercadorias (eletroeletrônicos, acessórios para celular, 


\section{Revista Nacional de}

celular, etc.), adquiridas em outros estados brasileiros, bem como no Paraguai. Do total de pessoas entrevistadas, 9\% declararam adquirir suas mercadorias em Vitória da Conquista, como também em outras cidades da região; $16 \%$ alegaram obtê-las tanto em outros estados nacionais, bem como no exterior; porém, a maioria, $75 \%$ dos entrevistados, afirmaram contrair suas mercadorias somente em outros estados brasileiros, sobretudo em São Paulo, Brasília, Pernambuco e Goiânia. Assim, verificase que o trabalho informal insere-se em uma divisão territorial do trabalho, possibilitando a redução do espaço-tempo entre produção e consumo, por meio de uma ampla rede de circulação de mercadorias.

Vale ressaltar ainda que há toda uma luta, por parte desses trabalhadores voltados para o comércio popular, no que concerne à organização/estruturação daquele espaço, de modo a propiciar melhores condições de trabalho para os vendedores ali presentes.

Ao que se refere ao mercado de consumo (aspecto socioeconômico), o mesmo é constituído em sua maioria por pessoas de baixa renda, que se direcionam a tais locais no intuito de satisfazerem algumas necessidades, isso de acordo com informações dos comerciantes informais da localidade em questão.

Observa-se ainda que os preços barateados em relação às lojas do comércio formal e o fato dos camelôs estarem concentrados na área central da cidade, pode acabar por facilitar e atender os anseios do consumidor, o que conduz mais uma vez a importância das estratégias de localização dessas atividades comerciais.

Contudo, é ainda importante considerar que não são apenas as pessoas de baixa renda que buscam os produtos que os camelôs comercializam, mas quem precisa de alguma mercadoria que está contida nesses espaços. Entra em foco então a questão da generalização e o fetiche das mercadorias, da obsolescência dos produtos e também das necessidades, do imenso prazer no ato de consumir (MONTESSORO, 2006).

Conforme já dito, além da Feira do Paraguai, pode-se observar ainda a presença de vendedores ambulantes em vários outros pontos estratégicos do centro 


\section{Revista Nacional de}

Gerenciamento de Cidades

principal de Vitória da Conquista, sobretudo em função do grande fluxo de pessoas que se constituem em potenciais consumidores. Dentre os vários pontos estratégicos, a Praça da Bandeira pode ser citada como exemplo por constituir-se em um local onde se encontram um número considerável de camelôs que diariamente se instalam nos 142 blocos (barraquinhas) ali presentes.

Nessa praça, há uma grande variedade de mercadorias a serem vendidas, tais como bolsas, bonés, bijuterias, artesanatos, confecções, etc. De acordo com os comerciantes que trabalham naquele local $7 \%$ das mercadorias ali comercializadas são de fabricação própria; $18 \%$ são provenientes de outras cidades da Bahia (Conquista e região); entretanto, a maioria, $75 \%$, são adquiridas em outros estados brasileiros, sobretudo em São Paulo, Pernambuco, Minas Gerais, Goiás e Santa Catarina. Desse modo, mais uma vez se torna evidente a existência de uma rede de circulação de mercadorias possibilitada pelo comércio informal.

A observação empírica nessa referida localidade possibilitou notar uma total falta de infraestrutura do local, na medida em que as mercadorias ali comercializadas encontram-se sujeitas a assaltos, roubos, bem como as intempéries climáticas, tais como sol, chuva, etc. Nessa mesma Praça também se encontra o Mercado de Artesanato de Vitória da Conquista, criado pela Secretaria de Educação e Cultura. No interior do referido Mercado existem 43 blocos, sendo que as pessoas que deles fazem uso pagam a Prefeitura uma taxa simbólica no valor de $R \$ 12,00$ ao mês pela ocupação dos mesmos. Porém, em virtude da própria limitação referente ao seu tamanho, a Prefeitura disponibilizou ainda 30 espaços, mais precisamente na calçada em frente ao Mercado. Desse modo, pode-se observar que tanto as ruas, quanto as calçadas configuram-se como parte integrante da lógica da mercadoria que envolve o centro, sendo que cada ponto é disputado de forma a possibilitar a circulação dos produtos, combinando os usos que vão desde a satisfação do consumo, à necessidade de deslocamento dos pedestres (MONTESSORO, 2006).

Dentre os trabalhadores informais desse mencionado local, $38 \%$ revelaram realizar a venda de serviços (costuras, em geral); os demais (62\%), afirmaram dedicar-se 
Revista Nacional de

Gerenciamento de Cidades

a venda de mercadorias. Assim, verifica-se que a questão preponderante não é a venda de serviços e sim de mercadorias, sendo que a redução espaço-tempo entre produção e consumo possibilitada por esse tipo de atividade, faz com que essas mercadorias cheguem de forma mais rápida ao público consumidor.

Observa-se ainda que os produtos ali comercializados são bastante diversificados: linha de bordado, artesanato de madeira, bonecas, livros, etc., sendo tanto de fabricação própria $(37 \%)$, bem como provenientes de outras cidades da região, sobretudo de Maracás e Jequié (63\%). Ao que se refere ao mercado de consumo, constata-se que esse não se restringe apenas a Vitória da Conquista, pois muitos desses produtos são encaminhados para outras cidades da região e até mesmo para outros estados, conforme afirmam os comerciantes informais da localidade em questão.

Contudo, além da abordagem de alguns aspectos relevantes referentes às principais áreas de comércio popular na cidade de Vitória da Conquista, para um maior entendimento da temática em questão, faz-se importante analisar também a estrutura urbana, de modo a se observar como os espaços de circulação e de troca estão dispostos, mas, sobretudo, articulados.

Tida como um produto social, a estrutura urbana provém da relação entre forma, função e retrato momentâneo do processo (WHITACKER, 2010), devendo-se ainda considerar que em sua análise, as funções e os usos das diferentes áreas são preponderantes. É importante observar então que esses camelôs se encontram em uma área periférica do centro, apresentando uma proximidade a Bancos (Caixa Econômica Federal; Banco do Brasil; Bradesco), a lojas de departamento (Insinuante; Marisa; Ricardo Eletro; Ponto Frio; Esplanada), ao terminal urbano, para onde convergem inúmeras pessoas, destacando-se as ações espontâneas quanto às práticas de consumo dos produtos oferecidos pelos camelôs ali presentes.

Cabe destacar ainda a coexistência entre as atividades comerciais formais e informais no centro comercial conquistense (Figura 2), o que aqui se infere que provavelmente se constitua em zonas de conflito na luta pelo território. 
Revista Nacional de

Gerenciamento de Cidades

\subsection{A ordenação do trabalho informal}

De um modo geral, pode-se dizer que a atuação do Estado no espaço urbano capitalista, visa criar condições que viabilizem o processo de acumulação e a reprodução das classes sociais, de modo a tornar viáveis tanto a atividade econômica, como também o processo de diferenciação social (CORRÊA, 1995). Percebe-se ainda o interesse público no fortalecimento das atividades comerciais e de serviços na área central desta cidade, podendo-se verificar no próprio Plano Diretor Urbano de Vitória da Conquista (PDU), a presença de algumas diretrizes que visam principalmente o fortalecimento do centro tradicional de comércio e serviços (promovendo a sua requalificação e melhoria), bem como a implantação de empreendimentos privados nessa localidade.

Dentre os vários princípios norteadores do PDU de Vitória da Conquista, pode-se destacar o que diz respeito à necessidade de fortalecimento do papel regulador do setor público e valorização das suas funções de planejamento, controle e articulação. Ao que se refere ao planejamento da organização territorial, verifica-se que esse deve priorizar as atividades econômicas, comerciais e de serviços, consideradas estratégicas para o desenvolvimento do município, bem como a organização das mesmas no território, de acordo com Dec-Lei n 1.385/2006 de 26 de dezembro de 2006.

Entretanto, além do PDU de Vitória da Conquista, verifica-se ainda a necessidade do uso de outros instrumentos de política administrativa, no que concerne a organização territorial do espaço urbano. Como exemplos podem ser citados o Código de Polícia Administrativa do município de Vitória da Conquista (Código de Posturas) e o Código Tributário, dentre outros.

Com relação ao Código de Polícia Administrativa (Código de Posturas), verifica-se que o mesmo tem como finalidade estabelecer normas de polícia administrativa de competência do município em matéria de proteção ao meio ambiente, a saúde e a ordem pública; a ele compete também regular as relações entre o poder público local e os munícipes, bem como o funcionamento dos 
Revista Nacional de

Gerenciamento de Cidades

estabelecimentos industriais, comerciais e prestadores de serviços, de acordo com Dec-Lei n695/93 de 02 de fevereiro de 1993.

No que diz respeito à regulação das atividades comerciais, verifica-se neste Código a proibição do funcionamento de qualquer tipo de estabelecimento comercial, inclusive os de caráter eventual, no território do município sem a licença prévia da administração municipal. É importante ressaltar que a concessão da licença deverá sempre obedecer às normas de vigilância sanitária, do Código de Obras, do Código Ambiental, do Código de Polícia Administrativa e do Código Tributário do município de Vitória da Conquista.

Entretanto, além da licença do poder público municipal (sendo essa pessoal e intransferível), para o exercício do comércio eventual, o interessado deverá também ser matriculado no cadastro geral de contribuintes do município. Constata-se ainda que a prioridade para o exercício desse tipo de comércio é concedida pelo poder executivo municipal, às pessoas sindicalizadas ou deficientes físicos, isto de acordo com o artigo 136 do Código de Posturas do município de Vitória da Conquista.

É importante que se compreenda que as atividades comerciais de caráter eventual, englobam não somente as atividades comerciais exercidas em determinadas épocas do ano (em períodos festivos e comemorações populares), mas também o comércio em instalações removíveis tais como barracas, tabuleiros, balcões, mesas, trailers e semelhantes, colocadas em logradouros públicos. Quanto aos locais e os horários para o exercício desse tipo de comércio, compete ao poder executivo municipal defini-los, conforme Dec-Lei n695/93 de 02 de fevereiro de 1993.

Especificamente com relação aos locais para o exercício do "comércio eventual", é importante enfatizar que os mesmos devem ser previamente delimitados pelo poder público, de modo a não impedir ou prejudicar o livre trânsito de pedestres ou veículos nas ruas, praças, passeios, estradas e caminhos públicos. Vale ainda ressaltar o fato de que os mesmos devem apresentar perfeitas condições de higiene e limpeza, cabendo ao comerciante ou prestador do serviço, se empenhar para que tais condições sejam mantidas. 
Revista Nacional de

Gerenciamento de Cidades

Verifica-se que essa cobrança se dá de forma mais criteriosa, sobretudo no exercício do comércio eventual voltado para o gênero alimentício, observando-se que, além da licença, os ambulantes deverão também portar obrigatoriamente a caderneta do Serviço de Fiscalização de Polícia Administrativa (SFPA) e o atestado médico que demonstre não existir impedimentos para o exercício deste tipo de comércio, isto de acordo com o artigo 135 do Código de Posturas.

Já com relação ao horário de funcionamento, se observa que os estabelecimentos comerciais, de um modo geral, têm liberdade de funcionamento nos dias úteis, sábados e domingos, desde que sejam observadas as proibições da legislação do trabalho aos empregados. É importante frisar que a não observância das referidas exigências, poderá implicar na apreensão de mercadorias postas à venda, bem como a aplicação de multas, cabendo ao poder executivo municipal e, em geral, aos servidores municipais, zelar pela execução dos instrumentos de Polícia Administrativa, por meio da realização de inspeções periódicas.

Entretanto, para o atendimento não somente dessas como também das demais diretrizes do PDU e do Código de Posturas, o município poderá dispor de todos os instrumentos tributários previstos no Estatuto da Cidade. Sob tal justificativa, impõe-se então a cobrança de taxas também para exploração de atividades em logradouros públicos, devendo essas corresponder às despesas do município concernentes a fiscalização e vistoria dos diversos estabelecimentos (Lei n 1.385/2006).

No caso específico do exercício de comércio eventual ou ambulante, o pagamento da taxa deve ser realizado no início da atividade (antes mesmo da concessão do alvará de licença), bem como nos casos de renovação da licença (anualmente), de acordo com o Dec- Lei n 1.259/2004 de 22 de dezembro de 2004, que institui o Código Tributário do município de Vitória da Conquista.

Conforme o Código Tributário, tanto a falta de requerimento da licença para o inicio de exploração de atividade, a falta de recolhimento da licença anual, bem como falsa declaração para obtenção da isenção da taxa, são consideradas infrações ao Plano Diretor Urbano do município e Código de Polícia Administrativa, ficando o infrator 
Revista Nacional de

Gerenciamento de Cidades

sujeito ao pagamento de multas (cujo valor é correspondente ao tipo de infração); além da aplicação de multas, pode ainda ocorrer apreensão de mercadorias e documentos que constituam prova material de infração à legislação tributária do município. A depender do caso, após a apreensão, esses bens poderão ser leiloados ou até mesmo doados a instituições de caridade e demais entidades de assistência social.

É importante ressaltar que a concessão de qualquer isenção de tributos referidos no Código Tributário municipal, somente poderá se efetivar através da lei municipal específica, de modo que, ficam isentos da taxa os deficientes físicos, visuais, excepcionais e inválidos que exerçam (individualmente) pequeno comércio ou prestação de serviços. À Secretaria de Finanças, pelos órgãos especializados, cabe então a fiscalização do cumprimento das normas da legislação.

Especificamente com relação ao exercício do comércio eventual, atualmente tem-se observado certo incentivo para que os trabalhadores autônomos saiam da informalidade e se tornem um Microempreendedor Individual (MEI), ao recolherem contribuições para a Previdência Social e impostos para estados e municípios. De acordo com a Receita Federal (2009), pode ser enquadrado como Microempreendedor Individual o profissional autônomo que receba a renda máxima bruta de até $\mathrm{R} \$ 36$ mil por ano. Para as empresas mais recentes, o Comitê Gestor do Simples Nacional (CGSN), determinou por meio da Resolução 58/09, que o enquadramento no $\mathrm{MEl}$ obedeça o limite de renda de $R \$ 3$ mil, sendo esse valor multiplicado pelo número de meses entre a abertura e o final do exercício.

De acordo com Carvalho (2009), ao recolher esses valores o Microempreendedor Individual ganha direitos trabalhistas e previdenciários que não tinha como autônomo, tais como: possibilidade de legalização do negócio; direito aos benefícios da Previdência Social; registro da empresa no Cadastro Nacional das Pessoas Jurídicas (no CNPJ); comprovação de renda (o que poderia facilitar a aquisição de empréstimos bancários com taxas reduzidas); possibilidade de emissão de notas fiscais mediante vendas de mercadorias, dentre outras. 


\section{Revista Nacional de}

No entanto, é preciso analisar até que ponto estas de fato se constituem em vantagens para os trabalhadores informais, de forma a oferecer maior segurança e possibilidade de crescimento aos mesmos. É importante se ter em mente a questão da funcionalidade do trabalho informal ao sistema do capital, como já abordado anteriormente, visto que, sob o capitalismo, visa-se primordialmente a obtenção de lucros em patamares cada vez mais elevados e não a satisfação das necessidades dos indivíduos, sobretudo do proletariado (que se encontra na base da pirâmide social). Partindo de tal pressuposto, verifica-se então o expressivo interesse das instituições governamentais, no que concerne a criação de mecanismos de fiscalização e regulação sobre o mundo do trabalho, vindo esses a se constituírem em formas de controle da subordinação e subsunção do trabalho informal e do desemprego ao capital.

\section{Considerações finais}

Mediante o exposto, na presente pesquisa pôde-se constatar que as atividades comerciais informais do centro comercial principal da cidade de Vitória da Conquista/BA, articulado e atrelado às funções do mesmo como expressão de espaços de consumo, contribui para a afirmação da centralidade intraurbana. A partir do entendimento da produção do espaço urbano (enquanto processo constituinte e constituído da produção social e, portanto, econômica, e cuja lógica de produção é orientada para o consumo) tal análise foi aqui fundamentada na prática do consumo sob o contexto da sociedade urbana, enfatizando-se o consumo do espaço, além da reprodução do capital que permeia essas relações. De forma enfática, foi evidenciada ainda a questão da apropriação de uma dada parte desse espaço para que o círculo da mercadoria/consumo/lucro se concretize, visto que o consumo de mercadorias e até mesmo do espaço, se estende a todos.

Com relação à ação do poder público sobre as atividades comerciais informais, constatou-se a atuação do mesmo enquanto agente regulador, legitimador 


\section{Revista Nacional de}

Gerenciamento de Cidades

e ao mesmo tempo limitador do trabalho informal, por meio de seus variados instrumentos de controle. Verificou-se, assim, que essa Instituição contribui para com o processo de subordinação e subsunção desse trabalhador à lógica do capitalismo, personificando, assim, os interesses do capital.

\section{Referências}

ABREU, B.R. Um olhar sobre a cidade média de Vitória da Conquista. In: Anais do II Simpósio Cidades Médias e Pequenas da Bahia. Disponível em:

<http://periodicos.uesb.br/index.php/ascmpa/article/view/3631>; Acesso em: abr. 2015.

BOTELHO, A. O urbano em fragmentos. A produção do espaço e da moradia pelas práticas do setor imobiliário. São Paulo: Annablume, 2007, p. 21-66.

CORRÊA, R. L. O espaço urbano. São Paulo: Ática, $3^{\circ}$ ed., 1995.

CORREA, R. L. Diferenciação socioespacial, escalas e práticas espaciais. Cidades, vol. 4, n. 6, 2007, p. 61-72.

INSTITUTO BRASILEIRO DE GEOGRAFIA E ESTATÍSTICA - IBGE. Nota técnica: Estimativas da população residente no Brasil e unidades da federação com data de referência em $1^{\circ}$ de julho de 2014. Disponível em: <ftp://ftp.ibge. gov. br/Estimativas de Populacao/Estimativas 2014/ estimativa dou 2014.pdf>; Acesso em: abr. 2015.

LEFEBVRE, H. O pensamento marxista e a cidade. Lisboa: Ulisséa, 1972, p. 29 a 76.

LENCIONI, S. CARLOS, A. F. A. Alguns elementos para discussão do espaço geográfico como mercadoria. In: Teoria e Método da Geografia. São Paulo: AGB, março, 1982.

MONTESSORO, C. C. L. Centralidade urbana e comércio Informal: os novos espaços de Consumo no centro de Anápolis-GO. Tese de doutorado. Programa de Pós-Graduação em Geografia. FCT - UNESP, 2006, 384 f.

SANTOS, M. O espaço dividido: Os dois circuitos da economia urbana dos países desenvolvidos. 2 ed. São Paulo: Edusp, 2004. 433p.

SPOSITO, M. E. B. O centro e as formas de expressão da centralidade urbana. Revista Geografia, São Paulo, UNESP, número 10: pp. 1-18.1991.

VITÓRIA DA CONQUISTA (Município). Lei n 695 de 02 de fevereiro de 1993. Dispõe sobre o Código de Polícia Administrativa (Código de Posturas), do município de Vitória da Conquista/BA.

VITÓRIA DA CONQUISTA (Município). Lei n 1.259 de 22 de dezembro de 2004. Dispõe sobre o Código Tributário do município de Vitória da Conquista/BA.

VITÓRIA DA CONQUISTA (Município). Lei no 1.385 de 26 de dezembro de 2006. Dispõe sobre o Plano Diretor do Município de Vitória da Conquista/BA. 

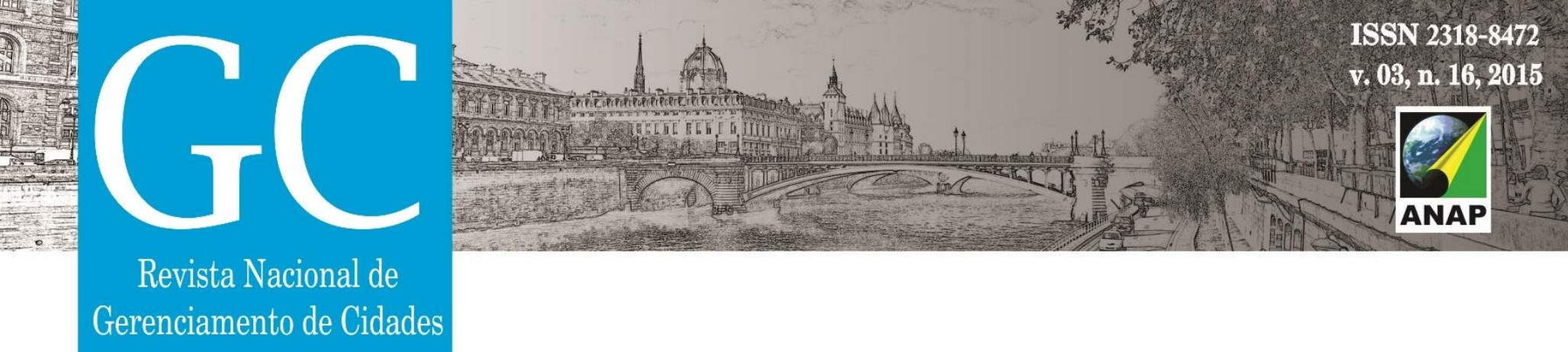

WHITACKER, A. M. Centralidade intraurbana e morfologia em cidades médias: transformações e permanências. In: XI Seminario Internacional RII y IV Taller de Editores RIER, junto ao Grupo temático 5: Ciudades intermedias: transformaciones y perspectivas, 2010, Mendoza, Argentina. Anales del XI Seminario Internacional RII y IV Taller de Editores RIER. Mendoza: Universidad Nacional del Cuyo, 2010. v.1. p.1-20. 